\title{
PERAWATAN ROTOR TURBIN DENGAN KALIBRASI KESETIMBANGAN
}

\author{
Yasir Amani \\ Fakultas Teknik Universitas Malikussaleh \\ Jl. Cot Tgk Nie-Reulet, Aceh Utara, 141 Lhokseumawe \\ Email : amaniyasir@yahoo.com
}

\begin{abstract}
Abstrak
Abstrak - Generator merupakan salah satu komponen vital dalam sebuah pembangkit listrik. Generator berfungsi untuk mengubah energi mekanik yang berasal dari turbin menjadi energi listrik. Melakukan pemeriksaan rutin dan berkala. Salah satu yang dilakukan misalnya pada rotor adalah : Balancing rotor. Untuk menganalisa pendistribusian massa yang tidak seimbang, dan mengetahui pengaruh sudut dan massa terhadap proses unbalance. Mamfaat perawatan turbin gas ini adalah mempermudah/mencegah kerusakan dengan mempergunakan teknologi digital dan menghemat biaya yang harus dikeluarkan oleh perusahaan akibat kerusakan yang lebih besar. Getaran tersebut timbul karena massa rotor tidak terdistribusi secaran merata, sehingga terdapat bagian yang mempunyai massa lebih besar dari pada bagian lainnya, turbin yang mempunyai hubungan dengan equipment. Rotor tidak mengalami keseimbangan yang sempurna adanya toleransi unbalance yang tertinggal, toleransi unbalance batas yang disebut allowable residual unbalance (kelebihan unbalance yang diizinkan), yaitu P1 $=2.05$ gr dengan sudut $2^{\circ}$ dan $\mathrm{P} 2=1.22$ gr dengan sudut $205^{\circ}$.
\end{abstract}

Kata Kunci : toleransi, unbalance, rotor, turbin, sudut

\section{Pendahuluan}

Generator merupakan salah satu komponen vital dalam sebuah pembangkit listrik. Generator berfungsi untuk mengubah energi mekanik yang berasal dari turbin menjadi energi listrik. Komponen utama generator terdiri dari bagian berputar yang dinamakan rotor dan bagian yang diam yang dinamakan stator. 
berbeda halnya dengan turbin, generator memerlukan pendinginan yang baik untuk memperpanjang umur pemakaian. hal ini disebabkan karena temperatur kerja yang sangat tinggi dapat menyebabkan kerusakan pada komponen generator. Terjadinya panas pada generator/ alternator disebabkan karena adanya rugi tembaga dan rugi Besi. Yang dimaksud dengan rugi tembaga adalah panas yang disebabkan karena adanya arus pembebanan yang mengalir melalui penghantar tembaga stator dan rotor. Sedangkan rugi besi adalah kerugian yang diakibatkan dari panas yang ditimbulkan dengan adanya arus pusar (eddy current) yang terjadi pada inti stator maupun rotor.

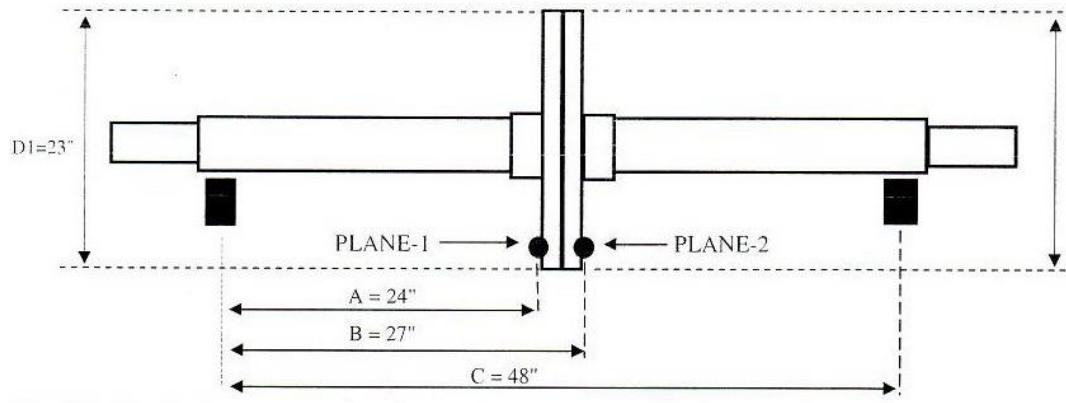

D2=23"

Gambar 1.1 Diameter rotor $(\mathrm{D} 1)$ dan $(\mathrm{D} 2)=23$ in, berat rotor $(\mathrm{W})=$ $242 \mathrm{lb}$, kecepatan rotor balancing $(\mathrm{N})=567 \mathrm{rpm}$

Melakukan pemeriksaan rutin dan berkala. Salah satu yang dilakukan misalnya pada rotor adalah : Balancing rotor. Disebut balancing rotor adalah suatu prosedur yang digunakan untuk memeriksa distribusi massa pada suatu rotor dan jika akan dilakukan penyetelan untuk memastikan bahwa getaran pada bantalan mengalami frekuensi sesuai dengan putaran operasi yang telah ditentukan oleh batas-batasnya, atau kalibrasi yang acuannya kebadan internasional. Penyebabnya ada beberapa kemungkinan salah satunya yaitu pendistribusian massa yang tidak seimbang. Ini akan dianalisa pada penelitian ini dan sekaligus mengkoreksinya. Untuk itu per menghitung nilai 
keseimbangan (balance preparation calculation) dan nilai akhir (max allowable unbalance calculation). Penelitian ini untuk menganalisa pendistribusian massa yang tidak seimbang, dan mengetahui pengaruh sudut dan massa terhadap proses unbalance. Mamfaat perawatan turbin gas ini adalah mempermudah/mencegah kerusakan dengan mempergunakan teknologi digital dan menghemat biaya yang harus dikeluarkan oleh perusahaan akibat kerusakan yang lebih besar.

\section{Metode dan Bahan}

\subsection{Alat dan Bahan}

Eksperimen dilakukan pada mesin balancing yang telah disesuaikan dengan keperluan pada machine shop. Mesin Balancing, dengan data :
a. Merk
: HD -27.2 Hopmann
b. Jenis
: Belt Drive;HHabasit
c. Motor Listrik
: EMERSON , $50 \mathrm{HP}$
d. Input Power : $3 \mathrm{PH}, 380 \mathrm{VAC}, 50 \mathrm{HZ}$
e. Drive Sistem : $65 \times 10 \neg \neg \wedge 6 \mathrm{~kg} \mathrm{~m} \wedge 2 / \min ^{\wedge} 2$
f. Speed Range : 60-6000 RPM

\subsection{Objek Penelitian}

Objek penelitian yang diamati dalam penelitian ini dibatasi pada Berat koreksi (lb) dan Sudut terkoreksi (o)

\subsection{Mekanisme Mendeteksi Rotor Unbalance}

Untuk mengetahui kerusakan yang terjadi pada suatu unit mesin dapat dilakukan dengan cara mendengarkan suara yang ditimbulkan serta getaran yang besar, dan memakai alat vibrasi, dengan memakai alat dapat mendeteksi lebih akurat dan langsung dapat mengetahui penyebab kerusakan.

\subsection{Langkah Pemeriksaan}

Untuk memperoleh data, dilakukan langkah-langkah pengerjaan rotor unbalance, yaitu : skema prosedur penelitian dapat dilihat pada gambar 3.3yaitu: 
- Data yang yang didapat dapat dilihat pada gambar 3.1 dimana 1X (kali) rpm menunjukan point $0.5 \mathrm{in} / \mathrm{sec}$. Unit dibawa ke gedung perawatan, dan pengambilan data-data yang diperlukan.

- Setelah diadakan pengukuran berat dan dimensi serta perhitungan berat / kecepatan (weight/speed) dan sistem pengerak maka kita dapat menentukan mesin mana yang harus kita pakai

- Rotor didudukan pada support, lalu dibersihkan.

- Memeriksa mesin balancing

- Hidupkan motor sehingga rotor ikut berputar

- Setelah pada layar indikasi terlihat bahwa putaran konstan, maka pada layar indikasi akan terlihat nilai unbalance pada sudutnya

- Setelah monitor dimatikan, kita beri tanda pada tempat yang dikoreksi sesuai sudut unbalance

- Pada titik-titik kedua bidang koreksi yang telah ditandai, ditempelkan massa sesuai dengan yang tercatat pada layar

- Pengujian ini harus dilakukan secara terus menerus sehingga massa pada layar akan mendekati nol. Dapat diambil kesimpulan bahwa ada kelebihan massa (unbalance) pada rotor. 


\subsection{Alur Pengujian}

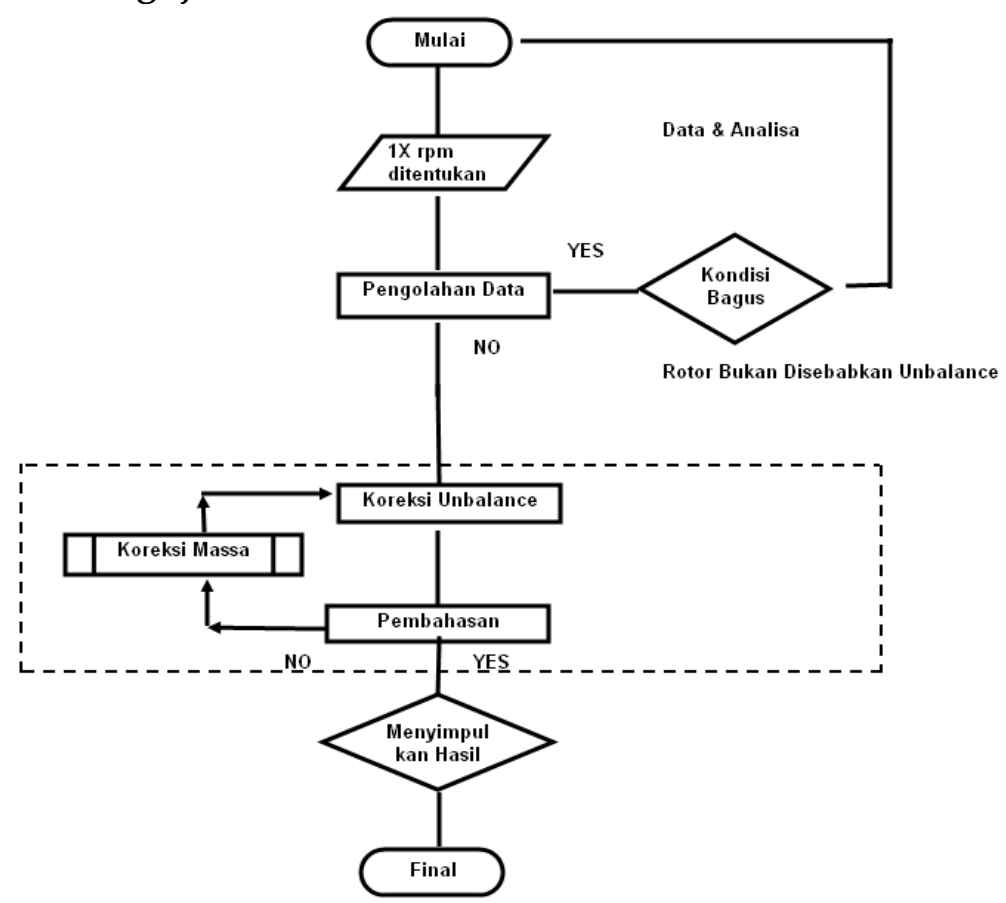

Gambar 2.1 Skema Prosedur Unbalance

\section{HASIL DAN PEMBAHASAN}

\subsubsection{Berat unbalance Sebelum Terkoreksi}

Diputar dari diam dan di naikan dengan berlahan- lahan sampai mencapai kecepatan $560 \mathrm{rpm}$, ini batas yang penulis lakukan.

3.1 Tabel pengamatan sebelum dibalance

\begin{tabular}{|c|c|c|c|c|}
\hline Tgl/Bln/Thn & P1 ( Gram $)$ & Sudut $\left({ }^{\circ}\right)$ & P2 ( Gram $)$ & Sudut $\left({ }^{\circ}\right)$ \\
\hline $11 / 01 / 2018$ & 110 & 192 & 137.8 & 353 \\
\hline
\end{tabular}

Sumber : Bacaan di layar pengamatan

Nilai- nilai di atas ditunjukkan dalan bentuk vektor yang berupa garis lurus yang penulis bedakan warna untuk plane I dengan plane II 


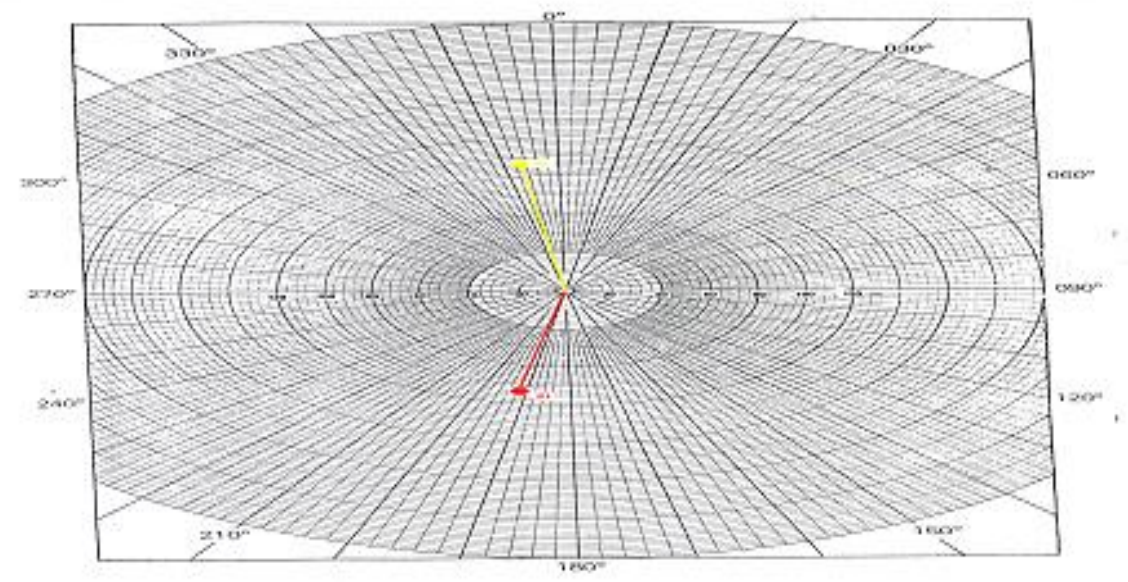

Gambar 3.1 Vektor Unbalance (sumber : data penelitian)

Dapat dilihat unbalance massa masih terlalu besar dari yang diizinkan. Proses koreksi pembuangan dari pada penambahan massa dengan pertimbangan waktu dan tempat koreksi. Setelah sudut telah diketahui dapat dilakukan pembuangan dengan cara digrinding secara berlahan sedikit demi sedikit dalam hal ini perlu ketelitian. Rotor diputar sampai mencapai kecepatan 560 rpm.

\subsubsection{Pembacaan Setelah Terkoreksi I}

Proses unbalance dilakukan,dengan prosedur yang sama dengan hari pertama. Rotor diputar dari kecepatan rendah lalu dinaikan secara berlahan-lahan sampai 560 rpm, disebabkan rotor dibiarkan semalaman, dengan harapan partikel- partikel yang menempel dapat hilang.

\subsection{Tabel Data Pengamatan Hasil pembacaan I}

\begin{tabular}{|c|c|c|c|c|}
\hline $\mathrm{Tgl} / \mathrm{B} \ln / \mathrm{Thn}$ & P1 ( Gram $)$ & Sudut $\left({ }^{\circ}\right)$ & P2 ( Gram $)$ & Sudut $\left({ }^{\circ}\right)$ \\
\hline $11 / 01 / 2018$ & 110 & 192 & 137.8 & 353 \\
\hline
\end{tabular}

Sumber : Data pengamatan penelitian 
Dilihat unbalance massa masih terlalu besar dari yang diizinkan, dan perlakuan selanjutnya apa dengan penambahan atau pengurangan massa, kemudian dari sudut yang didapat di grinding secara berlahan dan hati- hati sampai mencapai kecepatan $560 \mathrm{rpm}$.

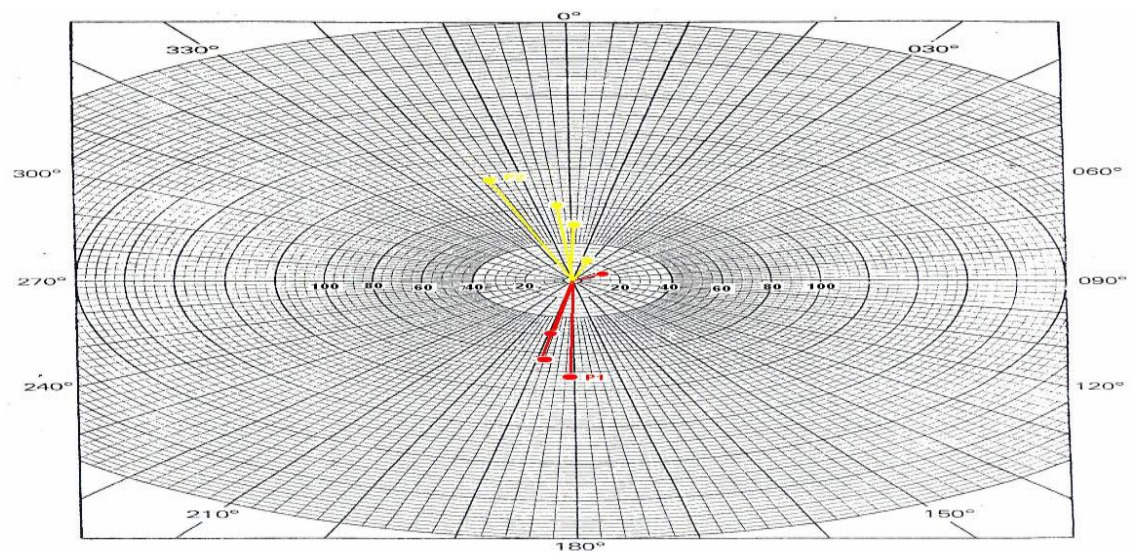

Gambar 3.2 Perubahan Vektor(sumber: data penelitian)

\subsubsection{Pembacaan II}

Proses unbalance selanjutnya dilakukan lagi,. Rotor diputar dari kecepatan rendah lalu dinaikan secara berlahan sampai 560 rpm, sampai kestabilan didapatkaan, waktu pencapaian satu sampai dengan dua menit.

\subsection{Tabel Hasil pembacaan II}

\begin{tabular}{|c|c|c|c|c|}
\hline Tgl/Bln/Thn & P1 ( Gram $)$ & Sudut $\left({ }^{\circ}\right)$ & P2 ( Gram $)$ & Sudut $\left({ }^{\circ}\right)$ \\
\hline \multirow{3}{*}{$13 / 02 / 2018$} & 18.1 & 164 & 29.1 & 14 \\
\cline { 2 - 5 } & 19.1 & 161 & 28.9 & 11 \\
\cline { 2 - 5 } & 18.9 & 163 & 29.3 & 12 \\
\cline { 2 - 5 } & 10.5 & 146 & 19.6 & 12 \\
\hline
\end{tabular}

Sumber : Data pengamatan penelitian

Telah mengalami beberapa perlakuan pada rotor seperti di grinding dan penghalusan (polish), yang dilajutkan dengan 
putaran sampai kestabilan didapatkan. Ini dapat dilihat dari angka-angka penunjukan dari layar monitor, yang apabila di vektorkan akan terlihat seperti gambar 3.3, dengan hasil ini masih terlihat jauh dari titik pusat. Ditahap ini juga akan dibuang massa yang telah ditentukan agar dapat mencapai nilai nol.

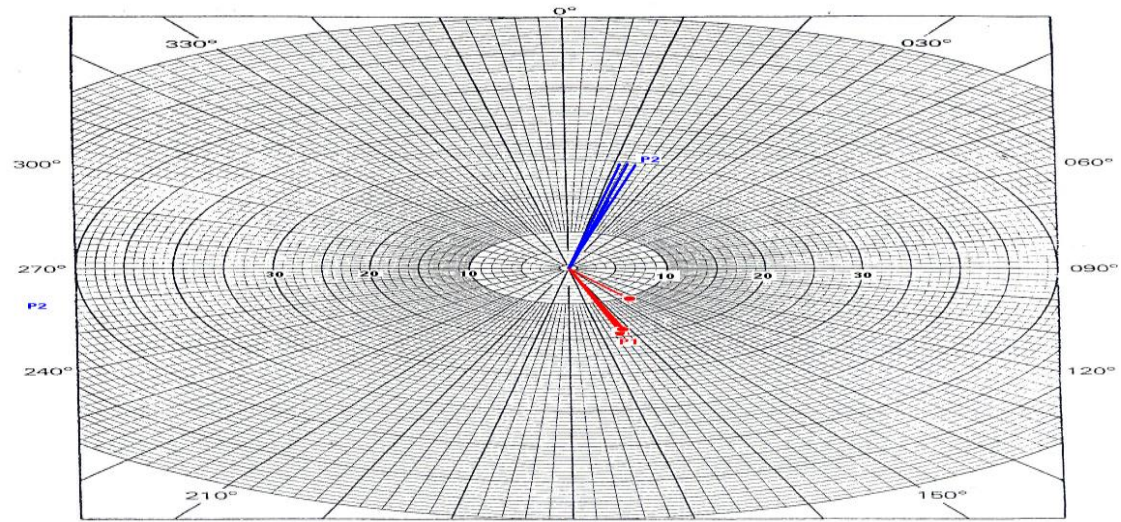

Gambar 3.3 Perubahan Vektor II (sumber : Data penelitian)

\subsubsection{Pembacaan III}

Proses unbalance dilakukan selanjutnya, dengan procedur yang sama. Rotor diputar dari kecepatan nol lalu dinaikan secara berlahan sampai $560 \mathrm{rpm}$, waktu pencapaian satu sampai dengan dua menit. Hasil penunjukan layar monitor, dapat dilihat pada tabel 3.4, angka- angka menjadi kecil. Pengerjaan semakin halus dan dibutuhkan ketelitian, baik dalam pembuagan berat massa.

3.4 Tabel Hasil pembacaan III

\begin{tabular}{|c|c|c|c|c|}
\hline Tgl/Bln/Thn & P1 ( Gram ) & Sudut $\left({ }^{\circ}\right)$ & P2 ( Gram $)$ & $\begin{array}{c}\text { Sudut }\left({ }^{\circ}\right. \\
)\end{array}$ \\
\hline \multirow{2}{*}{$14 / 01 / 2018$} & 11.1 & 148 & 9.5 & 12 \\
\cline { 2 - 5 } & 1.56 & 8 & 1.54 & 159 \\
\hline \multirow{2}{*}{ ggl/BIn/Thn } & P1 ( Gram ) & Sudut $\left({ }^{\circ}\right)$ & P2 ( Gram $)$ & $\begin{array}{c}\text { Sudut }\left({ }^{\circ}\right. \\
)\end{array}$ \\
\hline & 2.77 & 21 & 2.47 & 180 \\
\cline { 2 - 5 } & 2.89 & 16 & 2.58 & 174 \\
\cline { 2 - 5 } & 2.05 & 2 & 1.22 & 205 \\
\hline
\end{tabular}

Sumber : Data pengamatan penelitian 
Pada pemeriksaan selanjutnya rotor diputar dari nol ke 560 rpm secara berlahan- lahan dua sampai tiga menit. nilai- nilai jelas terjadi penurunan termasuk sudut- sudut terkoreksi juga. P1 = 1.89 gr dengan sudut $352 \square, \mathrm{P} 2=1.35$ gr dengan sudut $208 \square$. Hasil akhir di dalam membalancing rotor apakah sesuai standart, biasanya diberikan pemberat pada sudut sembarang. Menambahkan pemberat sebesar 62 gr pada sudut $0 \square$ pada P1. Dengan hasil : P1 = 63.6 gr dengan sudut $245 \square$, P2 $=13.5$ gr dengan sudut $2 \square$. Kemudian pemberat dipindahkan pada P2 dengan sudut $0 \square$, dengan hasil: $\mathrm{P} 1=10.6$ gr dengan sudut $245 \square$, $\mathrm{P} 2=58.5$ gr dengan sudut $2 \square$. Data yang didapat dari penambahan berat sebagai pembanding hasil tersebut sudah benar, selanjutnya pemberat tersebut dipindahkan dan diputar lagi untuk beberapa menit, dan didapat hasil penunjukan pada monitor : $\mathrm{P} 1=2.03$ gr dengan sudut $356 \square, \mathrm{P} 2=1.58$ gr dengan sudut $212 \square$, merupakan hasil final yang artinya proses balancing siap. 


\subsection{Pembahasan}

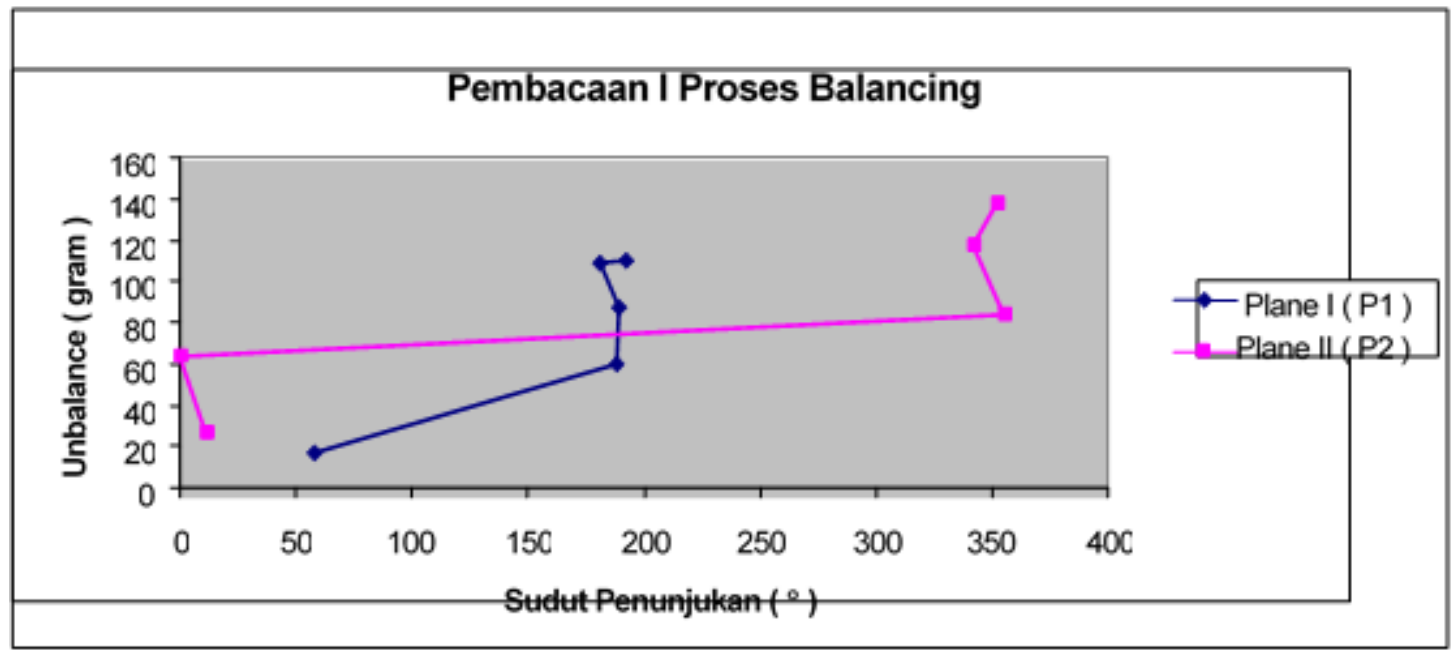

Sumber : Hasil pengolahan data

Gambar 3.4 Pembacaan I dalam proses balancing

Terlihat bahwa ada penurunan titik menuju titik pusat ( 0 ), dengan $\mathrm{P} 1=110$ gr dengan sudut $192^{\circ}$ dan $\mathrm{P} 2=137.8$ dengan sudut $353^{\circ}$, ini merupakan titik tertinggi sebelum terkoreksi dan $\mathrm{P} 1=16.9$ dengan sudut $58^{\circ}$ dan $\mathrm{P} 2=26.3$ dengan sudut $12^{\circ}$ merupakan titik terendah setelah terkoreksi pada tahap pertama. Cara digerenda pada titik yang ditunjukan oleh monitor. Rotor berlahan-lahan diputar dengan menaikan kecepatan mencapai 500 rpm selama beberapa menit dan distop, lalu diulang lagi sampai beberapa kali. 


\section{Pembacaan II Proses Balancing}

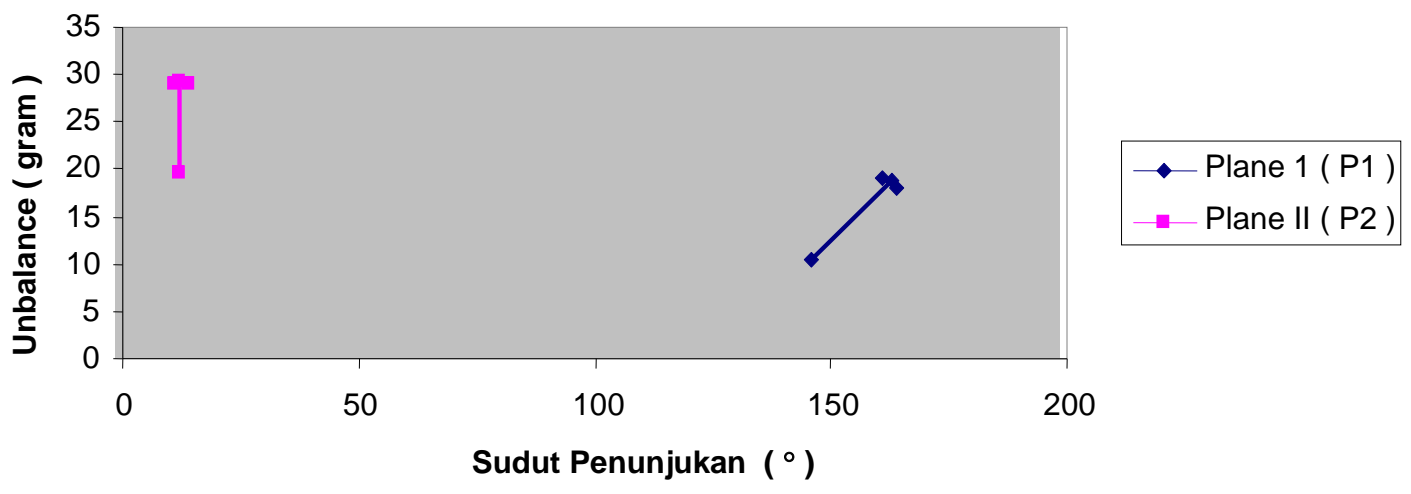

Sumber : Hasil pengolahan data

Gambar 3.5 Pembacaan Perlakuan II

Gambar 3.5 dari data pengamatan tanggal 13/02/2008 dapat dilihat $\mathrm{P} 1=18.1$ gr dengan sudut $164^{\circ}$ dan $\mathrm{P} 2=29.1$ gr dengan sudut $14^{\circ}$ mengalami penurunan, sedangkan untuk P1 = $10.5 \mathrm{gr}$ dengan sudut $146^{\circ}$ dan $\mathrm{P} 2=19.6$ dengan sudut $12^{\circ}$. Kedua-dua nilai terkoreksi (plane) masih belum mendekati titik 0 ini juga masih perlu dibuang berat dari ketidak unbalance dari rotor. Bagian dibuang harus mengikuti titik yang ditentukan oleh alat balancing yaitu point yang ada pada layar monitor. Dalam hal ini semakin mendekati dari standart rotor repair.

Sumber : Hasil pengolahan data

Gambar 3.6 Pembacaan Perlakuan III

Untuk P1= 11.1gr dengan sudut $148^{\circ}$ dan $\mathrm{P} 2=9.5$ gr dengan sudut $12^{\circ}$ nilai terkoreksi awal setelah proses ketiga. 


\section{Pembacaan III Proses Balancing}

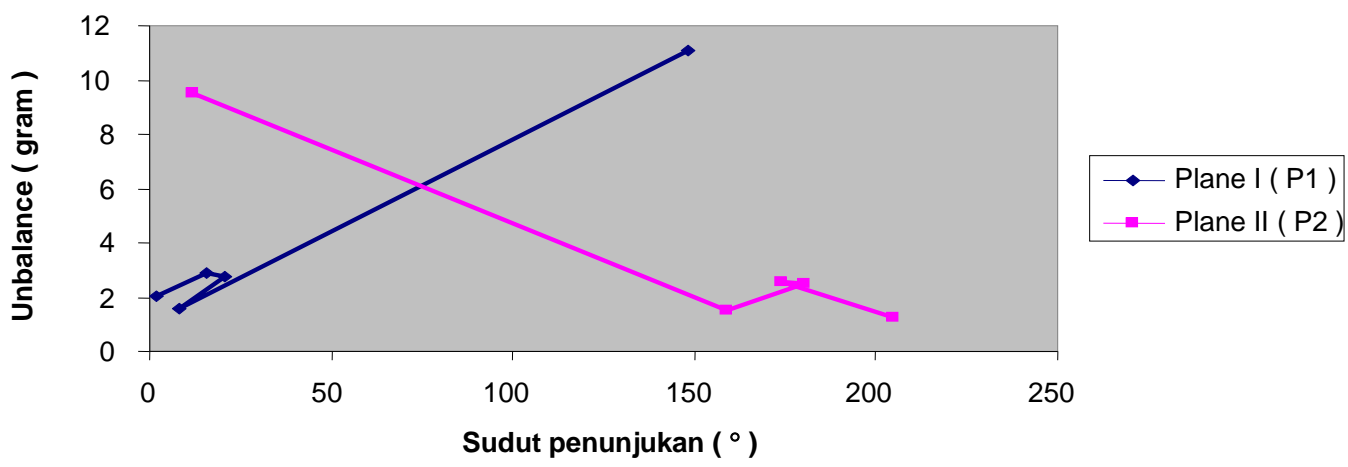

Sumber : Pembacaan Alat Vibrasi

Gambar 3.7 Getaran akibat unbalance

Grafik penunjukan kerusakan yang diakibatkan unbalance dan kerusakan terjadi pada bantalan (bearing). Untuk nilai terkecil dan dibawah sisa unbalance yang di izinkan yaitu P1= 2.05 gr dengan sudut $2^{\circ}$ dan P2=1.22gr dengan sudut $205^{\circ}$. Membalance suatu benda berputar mutlak yang diperhatikan adalah massa dari dari unbalance harus kecil.

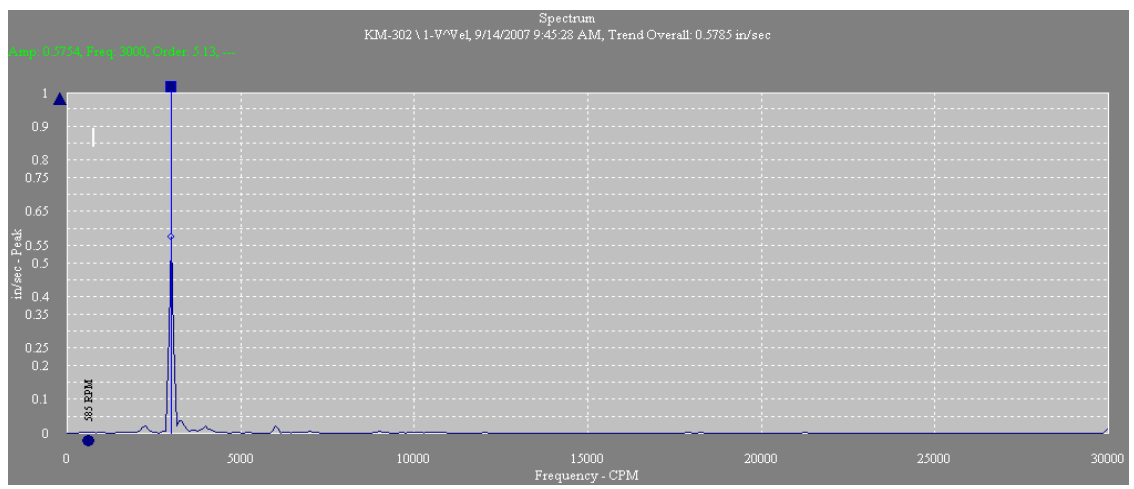

Sumber : Pembacaan Alat Vibrasi

Gambar 3.8 Getaran akibat kerusakan bantalan 


\section{KESIMPULAN DAN SARAN}

\subsection{Kesimpulan}

Getaran timbul karena massa rotor tidak terdistribusi secaran merata, sehingga terdapat bagian yang mempunyai massa lebih besar dari pada bagian lainnya, turbin yang mempunyai hubungan dengan equipment lainnya, misalnya mempunyai dua poros kopling, maka getaran dapat disebabkan oleh misalignment. Rotor tidak mengalami keseimbangan yang sempurna adanya toleransi unbalance yang tertinggal, toleransi unbalance batas yang disebut allowable residual unbalance (kelebihan unbalance yang diizinkan), yaitu $\mathrm{P} 1=2.05$ gr dengan sudut $2^{\circ}$ dan $\mathrm{P} 2=1.22$ gr dengan sudut $205^{\circ}$. Besar massa suatu rotor, maka unbalance sisa yang di izinkan semakin besar juga. Sudut yang dihasilkan tidak selalu menuju titik nol tetapi dimana posisi ketidak seimbangan yang lebih besar.

\subsection{Saran}

Balancing dengan menvariasikan putaran dan massa serta mempergunakan alat yang lebih moderen sehingga yang akan datang dapat menghasilkan hasil yang lebih akurat. 


\section{Daftar Pustaka}

Andrew J Winzenz Active Balancing Development, Product Manager Lord/BulaDyne,1665 Highland Drive,Ann Arbor USA

Balance Quality Requirements Of Rigid Rotor, IRD Balancing, The Practical Application Of Iso 1940/1

Crowford ,Arthur R., Crowford S, The Simplified Handbook of Vibration Analysis, Volume 1, SCI, Knoxville. 1992.

Ewins, D. J., Modal Testing-Theory and Practice, B\&K, Research studies press Ltd, Letchworth,1986.

Dennis h.Shreve Field Analysis And Balance Tools, IRD BALANCE 43085

New Directions For Machinery Reliability Training, Universal Technologies

Randall, RB, Frequency Analysis, Revision on september, Bruel \& Kjaer, Denmark, 1987.

Robert K. Vierck, Vibration Analysis, International Harper \& Row, Publisher, New York,1967.

Wowk, Victor, Machinary Vibration (Measurement \& Analysis), McGraw-Hill, USA. 1991.

Petroleum Industrial Training Consultant, Balancing Machine And Total Alignment Course.

Schenk Trebel,Fundamentals of Balancing ,535 Acorn Street,Deer Park,L.I,NY 11729 , January 1980

35 Acorn Street,Deer Park,L.I,NY 11729 , January 1980 